\title{
Allocating Resources for Glaucoma Care-A Review
}

\author{
Nkiru Nwamaka Kizor-Akaraiwe ${ }^{1,2}$ and Olusola Olawoye ${ }^{3,4}$ \\ 1. Enugu State University of Science and Technology Teaching Hospital Parklane, Enugu, Enugu State Nigeria; 2. College of Medicine, Enugu State \\ University of Science and Technology, Enugu, Enugu State, Nigeria; 3. University College Hospital, Ibadan, Nigeria; 4. College of Medicine, University \\ of Ibadan, Ibadan, Nigeria
}

DOI: https://doi.org/10.17925/USOR.2019.12.2.78

G laucoma affects over 70 million people worldwide, with the highest prevalence in Africa. The care of glaucoma is lifelong and costly; the annual direct cost per person for glaucoma medical treatment ranges from US\$394 in sub-Saharan Africa to US $\$ 1,055$ in the USA. Challenges of poor awareness, late presentation, acceptance, and adherence to treatment as well as follow-up care abound for glaucoma care. Available resources seem insufficient, hence the need to evaluate areas to channel resources in glaucoma care for maximum impact, especially in climes where they are limited. Even in high-income settings, resources are not unlimited. Different impact points exist in the care pathway, from early detection activities through awareness creation and screening, to appropriate diagnosis, treatment, follow-up care for monitoring disease stability as well as establishing pragmatic health system governance for long-term sustainability. This paper discusses several ways of allocating available resources to glaucoma care in order to target these impact points, as well as the pivotal role of provision of eye care as a social enterprise, especially in low-resource settings such as Africa, for better patient management outcomes.

\section{Keywords}

Glaucoma care, resource allocation, Africa

Disclosure: Nkiru Nwamaka Kizor-Akaraiwe and Olusola Olawoye have nothing to disclose in relation to this article.

Review Process: Double-blind peer review.

Compliance with Ethics: This study involves a review of the literature and did not involve any studies with human or animal subjects performed by any of the authors.

Authorship: The named authors meet the International Committee of Medical Journal Editors (ICMJE) criteria for authorship of this manuscript, take responsibility for the integrity of the work as a whole, and have given final approval for the version to be published.

Received: July 31, 2019

Accepted: September 23, 2019

Citation: US Ophthalmic Review, 2019;12(2):78-84

Corresponding Author: Nkiru Nwamaka

Kizor-Akaraiwe, ESUT Teaching Hospital Parklane,

PMB 1030, Enugu, Nigeria. E: nakaraiwe@gmail.com

Support: No funding was received in

the publication of this article.
The cost of glaucoma care is high ${ }^{1-3}$ and involves both the direct cost of eye consultations/examinations, investigations, medications or surgical interventions, as well as the indirect costs of loss of daily revenue during clinic visits, transport costs of self and care giver and the unquantifiable cost of psychological stress and blindness. These costs are recurrent with glaucoma being a lifelong disease. Glaucoma affects approximately 70 million people worldwide, about 7 million of whom are blind,, 5 with Africa having the highest prevalence of $4.32 \%{ }^{4.6} \mathrm{It}$ has been reported that the number of people living with glaucoma will increase to 111.8 million in 2040 and majority of these patients will be from Africa and Asia. ${ }^{5}$ The cumulative cost of care therefore becomes challenging both for the individual and for the health system, and this is likely to worsen as the number of glaucoma patients increases. Understanding the natural trend of the disease process and allocating resources to high-impact points will make for efficient management of resources especially in environments where they are limited.

Glaucoma is the second leading cause of blindness and the lead cause of irreversible blindness worldwide. ${ }^{4.7}$ Functional visual loss often occurs late in the disease course of glaucoma, which leads to late disease presentation and subsequently, late diagnosis. This is worse in resource-constrained economies. Undiagnosed disease in the population ranges from 50\% in developed economies to about $92-97 \%$ in developing economies.7. Additionally, about $30-70 \%$ of people in developing countries present as unilaterally blind. ${ }^{9-11}$ Early detection and appropriate, prompt treatment are major cornerstones in preventing glaucoma progression and blindness. ${ }^{12-14}$ Most early detections are from routine eye checks or opportunistic screening programs. ${ }^{15.16}$ Glaucoma care, therefore, spans from awareness creation, detection, diagnosis, and counseling to treatment and lifelong follow-up care. ${ }^{17}$

Glaucoma is a group of optic neuropathies characterized by selective and progressive loss of retinal ganglion cells; it manifests clinically by thinning and loss of the neuro-retinal rim and retinal nerve fiber layer with corresponding visual field loss. ${ }^{1{ }^{1}}$ Glaucoma can be classified into two main types based on the anterior chamber angle: the open (primary open angle glaucoma [POAG]) and the angle closure glaucoma (primary angle closure glaucoma [PACG]). Although POAG is more prevalent, PACG is more severe and more likely to result in irreversible blindness. ${ }^{4,19}$ PACG is often associated with high intraocular pressure (IOP) in its early stage and vision loss in the late stages. Treatment in the early stages is with laser peripheral iridotomies and medications to reduce IOP, and surgery in the later stages, which could be trabeculectomy with adjuvants or cataract extraction. Recently, however, clear lens extraction has been advocated as an option for first-line management in patients with PACG. ${ }^{20}$ 
The treatment of POAG typically involves medications, laser, or surgery. Surgery could include the traditional incisional surgeries, non-penetrating surgeries, or micro-invasive glaucoma surgery (MIGS). Laser surgery, such as laser trabeculoplasties, transscleral/endo-cyclophotocoagulation, or more recently, G6 ${ }^{\oplus}$ MicroPulse (IRIDEX, Mountain View, CA, USA) transscleral diode laser cyclophotocoagulation are also very important in the treatment of glaucoma. Medications for glaucoma include prostaglandin analogues, beta blockers, alpha agonists, carbonic anhydrase inhibitors, and the new Rho kinase (ROCK) inhibitors.

Most of these treatment options are available in developed economies but differentially available in limited dimensions in developing economies. Diagnosis and follow-up care entail the recurrent performance of examinations and tests such as IOP measurement, gonioscopy, central visual field, pachymetry, fundus photography, and optical coherence tomography (OCT) in order to monitor disease stability. ${ }^{2,22}$ Due to the huge burden that glaucoma places on the patient and on society, it is important that resources are allocated strategically to prevent needless blindness, and that barriers to access care are reduced, ensuring affordable services are delivered to all. Resources in healthcare often encompass the three M's: manpower (personnel), materials (instruments/equipment), and money (funds). Just as in any disease, these resources intertwine for effective glaucoma care delivery to any given population.

The aim of this review is to establish effective approaches for maximizing available resources in glaucoma care. Searches were performed using PubMed and Google Scholar platforms. Keywords included: "resources in glaucoma care", "challenges in glaucoma care", "glaucoma in various resource settings", "allocating scarce resources", "healthcare cost/personnel", and "screening and treatment options". One hundred and twenty-nine research materials were found, of which 93 were analyzed for this review.

\section{Manpower}

A health system is said to be as good as the personnel working in it. ${ }^{23}$ There is generally a shortage of manpower in healthcare and more so in glaucoma care, particularly in low-resource settings. The healthcare workforce in Africa, for instance, accounts for $1.3 \%$ of the world's healthcare workforce (Figure 1). ${ }^{24}$ There is lack of policy, training, and employment opportunities for mid-level manpower who serve more in primary and secondary levels of care. In low-resource economies, most of the population (80\%) reside in the rural settings, ${ }^{25}$ while most of the ophthalmic human resource (80\%) reside in urban areas. ${ }^{26}$ In Southeast Asia, in 2001, there were about 12,000 ophthalmologists, with 6,000 mid-level professionals which was grossly inadequate. ${ }^{23}$ After high school, the training of an ophthalmologist takes about 9-12 years, optometrist (4-6 years), ophthalmic nurse (4-6 years); while the training of an ophthalmic assistant, who can deliver eye care in rural settings takes about $1-2$ years. ${ }^{27}$

In Africa, there is also a dearth of eye care professionals. The average regional ratio of surgeons in sub-Saharan Africa is about 2.9 per million population while it is 83 per million in former socialist economies. ${ }^{26,28} \mathrm{In}$ 2015, among 27 government facilities in Botswana, there were only two general ophthalmologists, neither of whom had a subspecialty interest in glaucoma. ${ }^{29}$ In Nigeria, West Africa, for instance, up until 5 years ago when subspecialty training funding support came from the Commonwealth Eye Health Consortium, there were only about five glaucoma specialists in the
Figure 1: Proportion of the world's healthcare workforce in sub-Saharan Africa (human resource) ${ }^{24}$

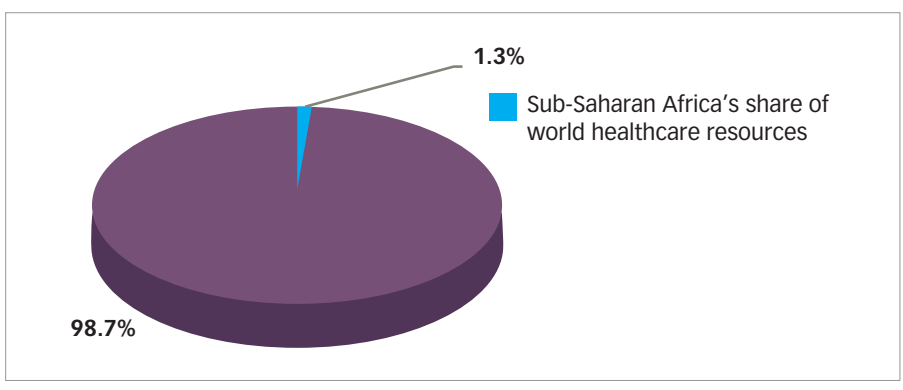

country (of about 190 million people), with glaucoma prevalence of 5.02\% in those $\geq 40$ years old.

Although it is important to train ophthalmologists, and indeed glaucoma specialists, to improve glaucoma care even in low-resource settings, the training of ophthalmic assistants may be cheaper and more cost effective. There have been successes in the use of ophthalmic assistants in the screening of glaucoma, both in the community and the clinic, in India. The diagnostic accuracy of the ophthalmic assistants in the clinic for detecting glaucoma was high for sensitivity but the specificity was quite low. The sensitivity was lower among ophthalmic assistants working in the community. ${ }^{30}$ Communitybased optometrists have also been used in the screening of glaucoma in the UK. There is evidence that the majority of patients with glaucoma and ocular hypertension were detected by community optometrists. ${ }^{31}$

Manpower is important in the screening and early detection of glaucoma. The increasing number of well-trained glaucoma subspecialists in Africa and other low-resource settings, in conjunction with the retraining of all the members of the eye care team, will improve the detection of glaucoma. Trained community optometrists have been valuable in providing glaucoma monitoring and follow-up care at primary and secondary levels. ${ }^{32}$

\section{Materials}

There are many instruments and equipment used in glaucoma care for screening, diagnosis, and treatment.

\section{Screening}

The standard and availability of screening tools often depends on the facility at which the screening is being conducted, e.g, at the community level or at the hospital, and screening can also vary between high- and low-income settings. Often, at the community level, screening tools are fewer and more basic compared to that of a hospital. Equipment at the community level could include simple pen torch, ophthalmoscopes, slit lamps, tonometers, and indirect lenses such as the 90D, 78D goniolenses, with or without the fundus camera and visual field machines, which could be the frequency-doubling machine, the frequency-doubling matrix, or other standard achromatic perimeters.

Screening devices have also progressed from direct ophthalmoscope with torch to hand-held non-mydriatic fundus cameras/visual field analyzers with telemedicine and OCT. The International Council of Ophthalmology recommends some basic equipment/medications for glaucoma care in low-, mid- and high-resource settings (Table 1). ${ }^{22}$ Smartphones have also 
Table 1: Glaucoma assessment and equipment needs—international recommendation ${ }^{22}$

\begin{tabular}{|c|c|c|}
\hline Clinical assessment & Minimum equipment requirement (low-resource settings) & Optimal equipment (intermediate- and high-resource settings) \\
\hline Visual acuity & $\begin{array}{l}\text { Near reading card; } \\
\text { Distance chart with five standard letters or symbols; } \\
\text { Pinhole }\end{array}$ & 3 or 4 m visual acuity lane with high-contrast visual acuity chart \\
\hline Refraction & $\begin{array}{l}\text { Trial frame and lenses; } \\
\text { Retinoscope, Jackson cross-cylinder }\end{array}$ & $\begin{array}{l}\text { Phoropter; } \\
\text { Autorefractor }\end{array}$ \\
\hline Pupils & Pen light or torch & \\
\hline Anterior segment & $\begin{array}{l}\text { Slit lamp biomicroscope; } \\
\text { Keratometer }\end{array}$ & Corneal pachymeter \\
\hline Intraocular pressure & $\begin{array}{l}\text { GAT; } \\
\text { Portable hand-held applanation tonometer; } \\
\text { Schiotz tonometer }\end{array}$ & $\begin{array}{l}\text { Tonopen; } \\
\text { Pneumotonometer }\end{array}$ \\
\hline Angle structures & $\begin{array}{l}\text { Slit lamp gonioscopy; } \\
\text { Goldman, Zeiss/Posner goniolenses }\end{array}$ & $\begin{array}{l}\text { Anterior segment OCT; } \\
\text { Ultrasound biomicroscopy }\end{array}$ \\
\hline $\begin{array}{l}\text { Optic nerve } \\
\text { (dilated if open angle) }\end{array}$ & $\begin{array}{l}\text { Direct ophthalmoscope; } \\
\text { Slit lamp biomicroscopy with hand-held 78- or 90-diopter lenses }\end{array}$ & $\begin{array}{l}\text { Fundus photography; } \\
\text { Optic nerve image analyzers }\end{array}$ \\
\hline Fundus & $\begin{array}{l}\text { Head-mounted indirect ophthalmoscope with 20-25-diopter lens; } \\
\text { Slit lamp biomicroscopy with 78-diopter lens }\end{array}$ & $\begin{array}{l}12-\text { and } 30 \text {-diopter lenses; } \\
60-\text { and 90-diopter lenses }\end{array}$ \\
\hline Visual field & Manual perimetry or automated white-on-white perimetry & $\begin{array}{l}\text { Frequency doubling technology; } \\
\text { Short wave automated perimetry }\end{array}$ \\
\hline
\end{tabular}

GAT = Goldmann Applanation Tonometer; OCT = optical coherence tomography.

been used for ophthalmoscopy especially in low-resources settings. Their availability and widespread use makes them beneficial in glaucoma screening, especially in remote places. Russo et al. showed a substantial agreement in vertical cup-to-disc ratio between smartphone ophthalmoscopy and slit lamp examination. ${ }^{33}$

\section{Diagnosis}

Diagnostic equipment includes all the equipment required for screening and for diagnosis, such as OCT (both anterior and posterior segment OCT), ОСT angiography, central visual field machines (standard automated perimetry), fundus cameras, and ultrasound biomicroscopy. The development and production of new equipment to optimize care, are ongoing. Studies in some African countries showed acute shortage of equipment for glaucoma diagnosis and follow-up, ${ }^{30,34,35}$ with approximately one-third of the equipment being non-functional especially in government facilities which serve a large proportion of the population..$^{35}$

\section{Treatment}

Methods for treating glaucoma range from simple medications/eyedrops to the new devices, such as MIGS and MicroPulse diode laser transscleral photocoagulation. Unlike in high-resource settings, where there are a plethora of glaucoma surgical techniques and devices to address mild to moderate glaucoma, in most low-resource settings, trabeculectomy with adjuvants is often the only glaucoma surgery available, ${ }^{34}$ and the glaucoma surgical rate is very low in these settings. ${ }^{11,30,36}$ The importance of antimetabolites, such as mitomycin C, 5 fluorouracil, and beta irradiation in dark-skinned persons during trabeculectomy, cannot be overemphasized. This is important in order to achieve optimal surgical results in the postoperative period. Glaucoma drainage devices (Ahmed Glaucoma Valve [New World Medical Inc. Cucamonga, CA, USA] and the Baerveldt Glaucoma Implant [Medline Industries Inc. Northfield, IL, USA]) can also be used to manage glaucoma. These treatment modalities, however, are quite costly and may not be readily available in low-income settings. The Aurolab aqueous drainage implant
(Aurolab, Madurai, India) is a low-cost, affordable glaucoma drainage implant with comparable efficacy with the Ahmed valve. This can be considered as an alternative in low-resource settings. ${ }^{37}$

\section{Money}

The cost of healthcare is huge and member states of the African Union consented to allocate at least $15 \%$ of their nation's budget to healthcare. ${ }^{38}$ While some nations like Tanzania, the Gambia, and Swaziland have allocated $>15 \%$, others like South Sudan and Angola allocated only 2-5\%. There is a huge discrepancy in the total global expenditures for health among countries, with the lowest country, Eritrea, spending US $\$ 12$ per person per annum and the highest country, USA, spending US\$8,362 per person per annum on healthcare. ${ }^{2}$ Healthcare budget significantly affects the funds available for the health of citizens (Figure 2). Most of the countries with a low healthcare budget often have suboptimal national health insurance schemes with a resultant high out-of-pocket expenditure.

Numerous reports have estimated the cost of treating glaucoma as extremely high. A cost-of-illness study showed that the USA spent more than US\$2.5 billion annually for glaucoma, of which, US\$1.9 billion was spent on direct costs and US\$0.6 billion as indirect costs. The estimated annual direct medical cost of treating newly diagnosed POAG was US $\$ 1,055$ per patient. ${ }^{39}$ The Danish registry data on 27,380 patients who began anti-glaucoma therapy between 2002-2007, revealed that annual healthcare costs per patient were $€ 305$ during their first treatment regimen, rising to $€ 744$ after three treatment changes..$^{40}$ At such costs, sustainability of medical therapy becomes quite uncertain. Adio et al. found in Rivers State, Nigeria, that middle- to low-income earners spent $50-100 \%$ of their monthly income on glaucoma medications, which is unsustainable. ${ }^{41}$ Similarly, annual costs of anti-glaucoma medication across sub-Saharan Africa is about US\$394 per patient, with a mean surgical cost per year of US $\$ 283$, and a mean direct non-medication cost year of US\$54. ${ }^{42}$ Studies have also shown that the cost of glaucoma management increases with 
Figure 2: World Bank comparison of GDP (nominal) per capita 2018 in USD

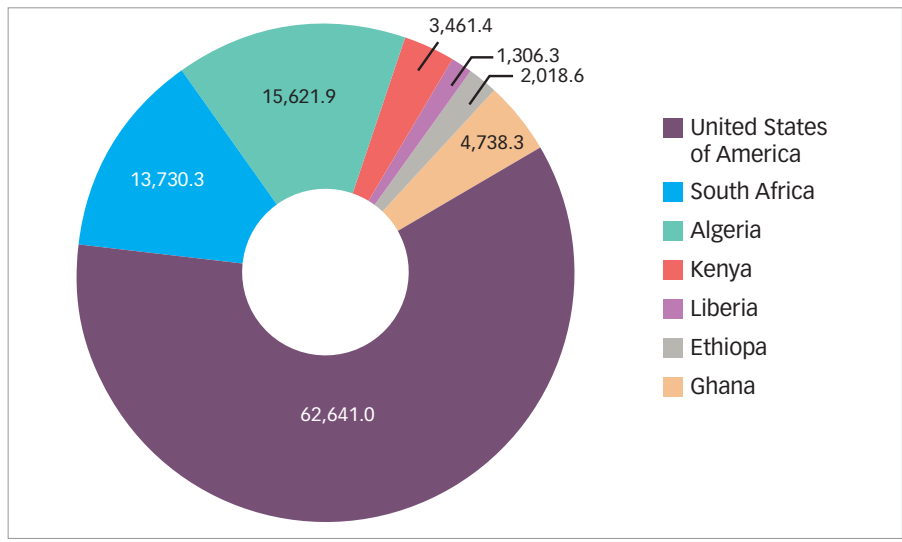

Source: World Bank National Accounts Data, and OECD National Accounts data files. ${ }^{94}$
Table 2: Screening criteria

Wilson and Jungner classic screening criteria

1. The condition sought should be an important health problem.

2. There should be an accepted treatment for patients with recognized disease.

3. Facilities for diagnosis and treatment should be available.

4. There should be a recognizable latent or early symptomatic stage.

5. There should be a suitable test or examination.

6. The test should be acceptable to the population.

7. The natural history of the condition, including development from latent to declared disease, should be adequately understood.

8. There should be an agreed policy on whom to treat as patients.

9. The cost of case-finding (including diagnosis and treatment of patients

diagnosed) should be economically balanced in relation to possible expenditure on medical care as a whole.

10. Case-finding should be a continuing process and not a "once and for all" project.

asymptomatic disease until the late stages, requires deliberate steps at identification in the early stages. In Africa, and most low-resource economies, $>90 \%$ of patients present late with advanced disease..$^{8,11}$ There is a significant linear increase in direct cost with worsening disease severity; therefore, resources channeled at early detection and appropriate, prompt treatment will likely drive down the overall cost of glaucoma care. Education, awareness-creation campaigns, and screening services are vital in early detection of glaucoma.50,51 Uptake of free screening services increases when they are brought closer to people, even those in high-resource societies. ${ }^{52,53}$ Population screening for glaucoma has generally not been found to be cost effective, especially as it does not yet meet all the Wilson and Jungner's criteria for screening (Table 2):54,55 however, arguments are arising for it in high-risk populations. ${ }^{56}$ Resources can therefore be channeled for early detection through different activities such as:

- organized public awareness programs;

- opportunistic screening of persons at risk by general ophthalmologists, general medical practitioners, optometrists;

Southeast Asia, especially India, has spearheaded innovations in eye care for decades. The periodic surveys, high-volume cataract surgery protocol developed by the Aravind Eye care system, the integration of eye care into the primary healthcare, the development of cost-effective school screening programs, as well as decentralized planning and service delivery which invested in eye health infrastructure and human resource capacity building, were major cornerstones in the huge success stories which could be replicable in low-resource settings. ${ }^{49}$

In the light of the above, it is pertinent, therefore, to evaluate areas to channel resources to in glaucoma care especially in climes where they are limited. Since glaucoma care covers different phases (awareness creation/public enlightenment, screening/detection, clinical diagnosis, investigations, treatment, follow-up), allocation of resources could be considered in the following four major impact points: early detection (awareness creation and screening), appropriate diagnosis and treatment, follow-up care, and health system governance (personnel/personnel distribution, data management systems, horizontal healthcare/integration).

\section{Impact points for resource allocation Early detection involving awareness-creation campaigns and screening activities}

The cost of glaucoma treatment is significantly reduced if treatment is commenced at an early stage of the disease. ${ }^{1,43}$ Glaucoma, being an
- active Glaucoma family screening program; this has a positive yield of up to $30 \%$ in high-risk populations such as black Africans. ${ }^{57.58}$ Therefore, resources channeled in active collaboration with glaucoma patients to contact and screen first- and second-degree relatives will be cost-effective;

- community-based screening using fixed sites and mobile teams among high-risk groups also has good yields. ${ }^{50}$ This is similar to the LV Prasad Eye Institute (LVPEI) eye-care model which has been endorsed by the WHO as a primary eye-care model;; 5

- telemedicine (teleglaucoma) is also a effective screening model. Teleglaucoma has been found to reduce cost, increase access to care, and improve healthcare service delivery, especially in rural areas. ${ }^{60}$ Hart and Jonathan et al., from the Wills Eye Hospital, Philadelphia, found $78.1 \%$ confirmation of glaucoma cases from telemedicine (which used fundus photo and IOP) with a comprehensive eye examination; ;1.62 and

- development of a simple, easy to use, affordable, sensitive, specific, stand-alone screening tool: this has been one of the major challenges of glaucoma in meeting the Wilson and Jungner screening criteria for screening. ${ }^{54,55}$ IOP, as a single screening tool for instance, has about $47 \%$ sensitivity and $97 \%$ specificity (for POAG only); 63 direct ophthalmoscopy has $65 \%$ sensitivity, $97 \%$ specificity; fundus photo has $89 \%$ sensitivity and $86 \%$ specificity; ${ }^{64}$ frequency-doubling technology has $79 \%$ sensitivity at 
90\% specificity; and OCT has 76-79\% sensitivity and 68-81\% specificity. ${ }^{65}$ Different combinations of these are usually used in screenings. Newer promising screening tools include the use of hand-held visual field analyzers, $\mathrm{N}$-goggle ${ }^{67}$ (a portable and wireless cloud—based, electroencephalogram device hoped to enable in-home and remote objective testing of the visual function deficits), smartphones, and artificial intelligence.

\section{Appropriate diagnosis and treatment}

Glaucoma diagnostic tests are expensive, particularly for patients paying out-of-pocket; in addition to this, the necessary equipment may not be available or may be non-functional in low-resource communities. ${ }^{35}$ Glaucoma is a progressive disease and treatment is centered around IOP reduction; glaucoma management centers should at least possess an IOP measuring instrument and a visual field analyzer to evaluate progression objectively. ${ }^{23}$ For the future, resources channeled to the development and availability of a simple comprehensive test that enables easy diagnosis will be cost-effective when compared with the numerous tests currently performed in order to confirm disease and monitor progress.

After diagnosis, the goal of glaucoma treatment is to maintain vision-related quality of life principally achieved by lowering the IOP to a level at which further glaucomatous damage would cease, at a cost the patient can sustain throughout life. ${ }^{68}$ Effective and well-tolerated initial treatment is the best approach to glaucoma treatment as it improves adherence and reduces disease progression. ${ }^{69}$

Trabeculectomy with adjuvant therapy has been advocated as first-line treatment in low-resource settings for its cost effectiveness, ${ }^{46,70}$ however, medications are still more commonly used despite being plagued with adherence issues. In their study in northern Ghana, Verrey et al. found that $84 \%$ of patients treated surgically achieved an IOP $<22$ mmHG after 6 months, compared to only $17 \%$ on medical therapy. ${ }^{45}$ Practice of trabeculectomy is low, which has been closely associated with inadequate surgical training during the residency program and poor patient acceptance. ${ }^{36,71}$ Surgical simulators have been found very useful in surgical training in high-resource settings. Resources spent on provision of good simulators will likely improve the glaucoma surgical rate and be cost effective.

Aqueous drainage devices are not commonly used in Africa, primarily due to the lack of expertise and the high cost. Though trabeculectomy has a lower cost per QALY, cheaper aqueous drainage implant options are now available. ${ }^{72}$ Aqueous drainage devices have close IOP reduction outcomes to those of trabeculectomy, and hence are good alternatives to trabeculectomy in low-resource settings, especially in cases where projected failure rates of trabeculectomy are high. MIGS has the potential of being more acceptable than incisional surgery because of its lower rate of complications and convenience. ${ }^{73}$ MIGS provides more surgical options for early to moderate glaucoma and also has the potential of being more acceptable than incisional surgery because of its convenience and lower rate of complication. However, the cost of most of the devices are prohibitive for low-resource economies. Though cheaper alternatives such as 360-degree goniotomy with 5-prolene suture can be explored.

Laser options have increasingly been advocated as primary therapy for mild to moderate glaucoma in both high- and low-income economies. ${ }^{74-78}$ Primary selective laser trabeculoplasty has been found to be more cost-effective than primary medical therapy in the management of POAG. ${ }^{74}$-79 Selective laser trabeculoplasty is safe, effective, convenient, and more readily acceptable, with effective repeatability potential. ${ }^{80}$ Resources channeled towards early detection and purchase of laser machine for a given population would, over time, be cost effective in the control of glaucoma blindness. MicroPulse diode laser transscleral photocoagulation has also been found to be effective, repeatable, and safe with a potential of being useful in low-resource settings; however, the high maintenance cost of non-reusable probe makes this currently unlikely.

\section{Follow-up care}

Follow-up care, which is lifelong, is as important as the diagnosis to prevent visual impairment and glaucoma blindness. Follow-up care involves adherence to scheduled consultation visits for repeat clinical examinations and investigations. In low-resource settings, finance for care is mostly from out-of-pocket expenditure..$^{41}$ Adherence to follow-up glaucoma care has been found to be as low as $0.0-17.6 \%$ in both high- and low-resource settings. $52,81,82$ The main reasons for lack of follow-up are cost (including costs of consultations, treatment, and investigations, as well as transport to the hospitals), lack of access to eye-care facilities, and sub-optimal awareness on disease condition. ${ }^{82}$

The Philadelphia Glaucoma Detection and Treatment project found that individuals in underserved communities took advantage of free eye examinations and returned for follow-up care when care was provided free of charge. ${ }^{83}$ Encouraging and strengthening national health insurance schemes, alongside public/private funding of screenings and eye care services, will likely yield better results. ${ }^{17}$ Sustainability of such a program is a challenge; however, certain models of care, such as the sight Reach Management model by International Eye Foundation, LVPEI, India model, and Aravind Eye care Systems, India, which transform eye clinics into social enterprise, have been found quite impactful in developing countries. ${ }^{59,84,85}$ By reducing the cost to serve the lowest $60 \%$ of the population, aligning centers exceeded their previous outputs on all metrics: number of patients examined, surgeries undertaken, percentage free treatment, revenue generated, cost recovery. These models could be replicated widely in low-resource economies. Co-ordinated, integrated care between primary, secondary, and tertiary centers, as earlier stated in the LVPEI model, can allow follow-up care to be closer to the people near their location, hence addressing the challenge of access. These secondary and primary centers could be manned by community optometrists and ophthalmic assistants. Patients whose target pressures are consistently not achieved are referred to higher centers.

Just as for screening tools, the development of a simple, inexpensive test to monitor progression of the disease, will greatly decrease the annual cost of glaucoma follow-up care. A promising diagnostic biomarker, growth differentiation factor 15 (GDF15), licensed by Q BioMed (New York, NY, USA) for determining the severity and progression of glaucoma, seems a hopeful option. ${ }^{86}$ It is aimed at being a simple, integrated, stand-alone diagnostic test performed in the physician's office with no external, expensive equipment. If proven effective in human clinical trials, it will be a major breakthrough in glaucoma follow-up care, with the added advantage of early detection over the conventional tests.

Glaucoma education and routine counseling is an integral part in promoting regular follow-up glaucoma care. ${ }^{87-89}$ Establishment of an active counseling 
unit, using local personnel (locally trained by the ophthalmologist), will contribute to adherence and follow up.

\section{Health system governance}

The establishment of health system governance and training of appropriate personnel has been identified as an important pillar in achieving universal eye health.90,91 The governance of the health system can be influenced by health and non-health governmental bodies. The government can engage several tools to improve eye health through a well-coordinated approach. This can include elaboration of policies, better allocation of budget/resources, strategic personnel training and distribution, strengthening of national health insurance schemes, integration of primary eye care into primary healthcare, implementation of quality standards, and regulation as well as introduction of incentives for eye care workers in rural areas. The inclusion of eye care into the national health insurance scheme, lowering of taxes for the importation of glaucoma medication, and increasing literacy rate on glaucoma by the ministry of education are viable ways to improve awareness, diagnosis, treatment, and follow-up care of glaucoma.92,93 Allocating resources to the training of mid-level personnel would likely enhance equitable distribution of glaucoma care in reaching the unreached, as well as provision for surgical skill updates of the surgeons.

\section{Conclusion}

Cost of glaucoma care is high and increases with disease severity. Appropriate manpower development, material and money utilization in a cost-effective way for early diagnosis, treatment and follow up will ultimately drive down the burden of glaucoma visual impairment and blindness.
1. Traverso CE, Walt JG, Kelly SP, et al. Direct costs of glaucoma and severity of the disease: a multinational long term study of resource utilisation in Europe. Br J Ophthalmol. 2005;89:1245-9.

2. Töteberg-Harms M, Berlin MS, Meier-Gibbons F. Increasing healthcare costs: can we influence the costs of glaucoma care? Curr Opin Ophthalmol. 2017;28:127-32.

3. Fiscella RG, Lee J, Davis EJ, Walt J. Cost of illness of glaucoma: a critical and systematic review. Pharmacoeconomics. 2009;27:189-98.

4. Quigley HA, Broman AT. The number of people with glaucoma worldwide in 2010 and 2020. Br J Ophthalmol. 2006;90:262-7.

5. Tham YC, Li X, Wong TY, et al. Global prevalence of glaucoma and projections of glaucoma burden through 2040: a systematic review and meta-analysis. Ophthalmology. 2014;121:2081-90.

6. Kyari F, Abdull MM, Bastawrous A, et al. Epidemiology of glaucoma in sub-Saharan Africa: prevalence, incidence and risk factors. Middle East Afr J Ophthalmol. 2013;20:111-25.

7. Budenz DL, Barton K, Whiteside-de Vos J, et al. Prevalence of glaucoma in an urban West African population: the Tema Eye Survey. JAMA Ophthalmol. 2013;131:651-8.

8. Leite MT, Sakata LM, Medeiros FA. Managing glaucoma in developing countries. Arq Bras Oftalmol. 2011;74:83-4.

9. Gyasi M, Amoako W, Adjuik M. Presentation patterns of primary open angle glaucomas in north eastern Ghana. Ghana Med J. 2010;44:25-30

10. Abdull MM, Gilbert CC, Evans J. Primary open angle glaucoma in northern Nigeria: stage at presentation and acceptance of treatment. BMC Ophthalmol. 2015;15:111.

11. Kayange PC, Nkume HB, Feyi-Waboso A, et al. Presentation of primary open angle glaucoma (POAG) at Lions Sight First Eye Hospital in Blantyre, Malawi. Malawi Med J. 2014:26:60-2.

12. Henson DB, Thampy R. Preventing blindness from glaucoma. BMJ. 2005;331:120-1.

13. Leske MC, Heijl A, Hyman L, et al. Factors for progression and glaucoma treatment: the Early Manifest Glaucoma Trial. Curr Opin Ophthalmol. 2004;15:102-6.

14. Rosenberg LF. Glaucoma: early detection and therapy for prevention of vision loss. Am Fam Physician. 1995;52:2289-98, 2303-4.

15. Olawoye O, Fawole OI, Teng CC, Ritch R. Evaluation of community eye outreach programs for early glaucoma detection in Nigeria. Clin Ophthalmol. 2013:7:1753-9.

16. Coleman AL. Glaucoma screening: a golden opportunity. Am Fam Physician. 1995;52:2167.

17. Thapa SS, Kelley KH, Rens GV, et al. A novel approach to glaucoma screening and education in Nepal. BMC Ophthalmol. 2008;8:21

18. Epidemiology of glaucoma in Asia. Tin Aung, Jonathan Crowston. Asia Pacific Glaucoma Outline 3rd editio ; Kugler Publication, Amsterdam, The Netherlands 2016. Available at: www.icoph. org/dynamic/attachments/resources/asia_pacific_glaucoma guidelines_2016_third_edition.pdf (accessed October 16, 2019).

19. Foster PJ. The epidemiology of primary angle closure and associated glaucomatous optic neuropathy. Semin Ophthalmol. 2002;17:50-8.

20. Brown RH, Zhong L, Lynch MG. Clear lens extraction as treatment for uncontrolled primary angle-closure glaucoma. J Cataract Refract Surg. 2014:40:840-1.

21. Sharma P, Sample PA, Zangwill LM, Schuman JS. Diagnostic tools for glaucoma detection and management. Surv Ophthalmol. 2008;53(Suppl 1):S17-32

22. Gupta N, Aung T, Congdon N, et al. ICO Guidelines for Glaucoma Eye Care. 2016. Available at: www.icoph.org/downloads/ ICOGlaucomaGuidelines.pdf (accessed October 16, 2019).

23. World Health Organization, Regional Office for South-East Asia. Comprehensive planning of human resources for eye care to meet the goals of vision 2020. The right to sight. Available at: https://apps.who.int/iris/handle/10665/204895? show=full (accessed October 16, 2019).

24. World Health Organisation. Global Health Observatory data repository Available at: https://apps. who.int/gho/data/node.main. HWF (accessed October 16, 2019).

25. Sheingate A. Agrarian Social Pacts and Poverty Reduction. 2008. Available at: http://unrisd.org/80256B3C005BCCF9/ (httpAuxPages)/13F125EBBAEC4FF9C1257AE5004E75BO/sfile/ Sheingate.pdf (accessed October 15, 2019).

26. Palmer JJ, Chinanayi F, Gilbert A, et al. Mapping human resources for eye health in 21 countries of sub-Saharan Africa: current progress towards VISION 2020. Hum Resour Health. 2014:12:44

27. Masnick K. Narrowing the gap between eye care needs and service provision: the service-training nexus. Hum Resour Health 2009;7:35

28. Al Motowa S, Khandekar R, Al-Towerki A. Resources for eye care at secondary and tertiary level government institutions in Saudi Arabia. Middle East Afr J Ophthalmol. 2014;21:142-6.

29. Razai MS, Jackson DJ, Falama R, et al. The capacity of eye care services for patients with glaucoma in Botswana. Ophthalmic Epidemiol. 2015:22:403-8.

30. Sinha SK, Astbury N. Evaluation of the effectiveness of ophthalmic assistants as screeners for glaucoma in North India. Eye (Lond). 2011;25:1310-6

31. Bowling B, Chen SDM, Salmon JF. Outcomes of referrals by community optometrists to a hospital glaucoma service. Br J Ophthalmol. 2005;89:1102-4.

32. Gray SF, Spry PG, Brookes ST, et al. The Bristol shared care glaucoma study: outcome at follow up at 2 years. Br $J$ Ophthalmol. 2000:84:456-63.

33. Russo A, Mapham W, Turano R, et al. Comparison of smartphone ophthalmoscopy with slit-lamp biomicroscopy for grading vertic cup-to-disc ratio. J Glaucoma. 2016;25:e777-81.

34. Kyari F, Nolan W, Gilbert C. Ophthalmologists' practice patterns and challenges in achieving optimal management for glaucoma in Nigeria: results from a nationwide survey. BMJ Open. 2016;6:e012230.

35. Adekoya BJ, Shah SP, Adepoju FG. Managing glaucoma in Lagos State, Nigeria - availability of human resources and equipment. Niger Postgrad Med J. 2013;20:111-5.

36. Kizor-Akaraiwe NN, Ogbonnaya CE. Practice of trabeculectomy by ophthalmologists in Nigeria. Niger J Clin Pract. 2017:20:507-11.

37. Pathak Ray V Rao DP. Surgical outcomes of a new affordable non-valved glaucoma drainage device and Ahmed glaucoma valve: comparison in the first year. Br J Ophthalmol. 2019:103:659-65

38. World Health Organization. The Abuja Declaration: ten years on. 2011. Available at: www.who.int/healthsystems/publications/ abuja_declaration/en/ (accessed November 28, 2019).

39. Kobelt-Nguyen $\mathrm{G}$, Gerdtham UG, Alm A. Costs of treating primary open-angle glaucoma and ocular hypertension: a retrospective, observational two-year chart review of newly diagnosed patients in Sweden and the United States. J Glaucoma. 1998:7:95-104.

40. Olsen J, Berdeaux G, Skov J. Glaucoma costs in Denmark in treatment naive patients. Acta Ophthalmol. 2013;91:25-31.

41. Adio AO, Onua AA. Economic burden of glaucoma in Rivers State, Nigeria. Clin Ophthalmol. 2012;6:2023-31.

42. Smith AF, Negretti G, Mascaro A, et al. Glaucoma control strategies in sub-Saharan Africa: a review of the clinical and health economic evidence. Ophthalmic Epidemiol. 2018;25:419-35.

43. Iskedjian $\mathrm{M}$, Walker J, Vicente $\mathrm{C}$, et al. Cost of glaucoma in Canada: analyses based on visual field and physician's assessment. J Glaucoma. 2003;12:456-62

44. Verrey JD, Foster A, Wormald R, Akuamoa C. Chronic glaucoma in Northern Ghana - a retrospective study of 397 patients. Eye (Lond). 1990;4:115-20.

45. Verrey JD, Foster A, Wormald R, Akuamoa C. Chronic glaucoma in Northern Ghana-A retrospective study of 397 patients. Eye. 1990:4:115-20.

46. Leibmann ML, Kim J. Trabeculectomy. In: Weinreb RN, Crowsto JG, Association of International Glaucoma Societies. Glaucoma surgery, open angle glaucoma : reports and consensus statements of the 2nd Global AlGS Consensus Meeting on glaucoma surgery--open angle glaucoma. Kugler Publications; Amsterdam, The Netherlands, 2005. Pages 57-6.

47. Burr J, Azuara-Blanco A, Avenell A, Tuulonen A. Medical versus surgical interventions for open angle glaucoma. Cochrane Database Syst Rev. 2012:9:CD004399

48. Kaplan RI, De Moraes CG, Cioffi GA, et al. Comparative cost-effectiveness of the Baerveldt implant, trabeculectomy with mitomycin, and medical treatment. JAMA Ophthalmol. 2015;133:560-7.

49. Murthy GV. Eye care in South Asia, 1988-2018: developments, achievements and future challenges. Community Eye Health. 2017;30:99-101.

50. Al-aswad LA, Joiner DB, Wang $X$, et al. Screening for glaucoma in populations at high risk: The eye screening New York project. Cogent Medicine. 2017:4:1367059.

51. Kizor-Akaraiwe NN, Monye HI, Okeke S. Awareness and knowledge about glaucoma and proportion of people with glaucoma in an urban outreach programme in Southeast Nigeria. BMJ Open Ophthalmol. 2017;1:e000018.

52. Rahmani B, Tielsch JM, Katz J, et al. The cause-specific prevalence of visual impairment in an urban population. The Baltimore Eye Survey. Ophthalmology. 1996;103:1721-6.

53. Fletcher $\mathrm{AE}$, Donoghue M, Devavaram J, et al. Low uptake of eye services in rural India: a challenge for programs of blindness prevention. Arch Ophthalmol. 1999:117:1393-9.

54. Andermann A, Blancquaert I, Beauchamp S, Déry V. Revisiting Wilson and Jungner in the genomic age: a review of screening criteria over the past 40 years. Bull World Health Organ. 2008;86:317-9.

55. Wilson JMG, Jungner G. Principles and practice of screening for disease Public Health Papers. 1968:34:163

56. Zhang L, He M. Is population-based glaucoma screening cost-effective in China? Lancet Glob Health. 2019:7:e833-4.

57. Nguyen RL, Raja SC, Traboulsi El. Screening relatives of patients with familial chronic open angle glaucoma. Ophthalmology. 2000;107:1294-7.

58. Rajendrababu S, Gupta N, Vijayakumar B, et al. Screening first degree relatives of persons with primary open angle glaucoma in India. J Curr Glaucoma Pract. 2014:8:107-12.

59. Rao G, Khanna RC, Athota SM, al. Integrated model of primary and secondary eye care for underserved rural areas: The $L$ V Prasad Eye Institute experience. Indian J Ophthalmol. 2012;60:396-400.

60. Thomas S, Hodge W, Malvankar-Mehta M. The cost-effectiveness analysis of teleglaucoma screening device. PLOS One. 2015; 10:e0137913.

61. Helzner J. Telemedicine screening effort deemed a success. 2019 Available at: https://www.glaucomaphysician.net/issues/2019/ june-2019/telemedicine-screening-effort-deemed-a-success (accessed October 16, 2019).

62. Owsley C, Rhodes LA, MCGwin G, et al. Eye care quality and accessibility improvement in the community (EQUALITY) for adults at risk for glaucoma: study rationale and design. Int J Equity Health. 2015;14:135.

63. Tielsch JM, Katz J, Singh K, et al. A population-based evaluation of glaucoma screening: The Baltimore Eye Survey. Am J Epidemiol. 1991:134:1102-10.

64. Harding SP, Broadbent DM, Neoh C, et al. Sensitivity and specificity of photography and direct ophthalmoscopy in screening for sight threatening eye disease: the Liverpool Diabetic Eye Study. BMJ. 1995;311:1131-5.

65. Johnson CA, Fingeret M, Iwase A. F. Frequency Doubling Technology (FDT) Perimetry. In: Weinreb RN, Greve EL, Glaucoma Diagnosis Structure and Function: Reports and Consensus Statements of the 1st Global AlGS Meeting on "Structure and Function in the Management of Glaucoma". Kugler Publications: Amsterdam, The Netherlands, 2004;109-117.

66. Leibmann J, Bowd C, Medeiros FA, Schuman J. Optical Coherence Tomography (OCT). In: Weinreb RN, Greve EL. Glaucoma Diagnosis Structure and Function: Reports and consensus Statements of 
the 1st Global AlGS Meeting on "Structure and Function in the Management of Glaucoma". Kugler Publications: Amsterdam, The Netherlands. 2004;71-82

67. Medeiros FA. The nGoggle: a portable brain-based method for assessment of visual function deficits in glaucoma. 2016. Available at: www.researchgate.net/publication/316634406_The nGoggle_A_Portable_Brain-Based_Method_for_Assessment_of_ Visual_Function_Deficits_in_Glaucoma (accessed October 16 2019)

68. European Glaucoma Society. Terminolology and guidelines fo glaucoma. 2014. Available at: https://bjo.bmj.com/content/ bjophthalmol/101/4/1.full.pdf (accessed October 16, 2019).

69. Denis $\mathrm{P}$, Lafuma A, Berdeaux G. Medical outcomes of glaucoma therapy from a nationwide representative survey. Clin Drug Investig. 2004:24:343-52.

70. Omoti AE. A review of the choice of therapy in primary open angle glaucoma. Niger J Clin Pract. 2005;8:29-34.

71. Adekoya BJ, Onakoya AO, Shah SP, Adepoju FG. Surgical output and clinic burden of glaucoma in lagos, Nigeria. Glaucoma. 2014;23:41-5.

72. Pathak Ray V, Rao DP. Surgical outcomes of a new affordable non-valved glaucoma drainage device and Ahmed glaucoma valve: comparison in the first year. Br J Ophthalmol. 2019;103:659-65.

73. Richter $\mathrm{G}$, Coleman AL. Minimally invasive glaucoma surgery: current status and future prospects. Clin Ophthalmol. 2016;10:189-206

74. Gazzard G, Konstantakopoulou E, Garway-Heath D, et al. Selective laser trabeculoplasty versus eye drops for first-line treatment of ocular hypertension and glaucoma (LiGHT): a multicentre randomised controlled trial. Lancet. 2019;393:1505-16.

75. Realini $\mathrm{T}$, Olawoye $\mathrm{O}$, Kizor-Akaraiwe $\mathrm{N}$, et al. The rationale for selective laser trabeculoplasty in Africa. Asia Pac J Ophthalmo (Phila). 2018:7:387-93

76. Thomas R, Sekhar GC, Kumar RS. Glaucoma management in developing countries: medical, laser, and surgical options for glaucoma management in countries with limited resources. Curr Opin Ophthalmol. 2004;15:127-31.

77. Seck SM, Agboton G, Dieng M, et al. La trabéculoplastie au laser sélectif (TLS): notre expérience chez le noir africain. J Fr Ophtalmol. 2015;38:238-46.

78. Abdull MM, Broadway DC, Evans J, et al. Safety and effectiveness of primary transscleral diode laser cyclophotoablation for glaucoma in Nigeria. Clin Exp Ophthalmol. 2018;46:1041-7.

79. Lee R, Hutnik CML. Projected cost comparison of selective laser trabeculoplasty versus glaucoma medication in the Ontario Health Insurance Plan. Can J Ophthalmol. 2006;41:449-56.

80. Polat J, Grantham L, Mitchell K, Realini T. Repeatability of selective laser trabeculoplasty. Br J Ophthalmol. 2016;100:1437-41.

81. Robin AL, Nirmalan PK, Krishnadas R, et al. The utilization of eye care services by persons with glaucoma in rural south India. Trans Am Ophthalmol Soc. 2004;102:47-54.

82. Kizor-Akaraiwe NN. Follow-up and adherence to glaucoma care by newly diagnosed glaucoma patients in Enugu, Nigeria. Ophthalmic Epidemiol. 2019;26:140-6.

83. Hark L, Waisbourd M, Myers JS, et al. Improving access to eye care among persons at high-risk of glaucoma in Philadelphia — design and methodology: the Philadelphia Glaucoma Detection and Treatment Project. Ophthalmic Glaucoma Detection and Tre

84. Rahmathullah R, Barrows J, Sheffield VM. Transforming eye clinics and hospitals to sustainability - the International Eye Foundation's social enterprise model. European Ophthalmic Review. 2009;2:8-11.

85. Venkatesh P, Kumar S, Thulasiraj RD, Priya S. Replication of Aravind model - a strategy to develop sustainable eye care programmes. 2010. Available at: www.pointsdevue.com/article/ replication-aravind-model-strategy-develop-sustainable-eye-careprogrammes (accessed November 28, 2019)

86. Q Biomed Inc. Q Biomed licenses novel biomarker for monitoring glaucoma severity and progression from Washington University. 2019. Available at: www.globenewswire.com/new s-release/2019/03/11/1751199/0/en/Q-Biomed-Licenses-N ovel-Biomarker-for-Monitoring-Glaucoma-Severityand-Progression-From-Washington-Universityhtm (accessed October 16, 2019).

87. Do AT, Pillai MR, Balakrishnan V, et al. Effectiveness of glaucoma counseling on rates of follow-up and glaucoma knowledge in a South Indian population. Am J Ophthalmol. 2016;163:180-9.

88. Kyari F, Chandler $\mathrm{Cl}$, Martin M, Gilbert CE. So let me find my way, whatever it will cost me, rather than leaving myself in darkness: experiences of glaucoma in Nigeria. Glob Health Action. 2016;9:31886

89. Abdull MM, Gilbert C MCCambridge J, Evans J. Adapted motivational interviewing to improve the uptake of treatment for glaucoma in Nigeria: study protocol for a randomised controlled trial. Trials. 2014;15:149

90. World Health Organization. Universal eye health: a global action plan 2014-2019. Available at: www.who.int/blindness/actionplan/ en/ (accessed October 16, 2019).

91. Kyari F, Gilbert C, Blanchet K, Wormald R. Improving services for glaucoma care in Nigeria: implications for policy and programmes to achieve universal health coverage. Br J Ophthalmol. 2017;101:543-7.

92. Blanchet K, Patel D. Applying principles of health system strengthening to eye care. Indian J Ophthalmol. 2012;60:470-4.

93. Du Toit R, Faal HB, Etya'ale D, et al. Evidence for integrating eye health into primary health care in Africa: a health systems strengthening approach. BMC Health Serv Res. 2013:13:102.

94. The World Bank. World Bank National Accounts Data, and OECD National Accounts data files. Available at: https://data.worldbank. org/indicator/NY.GDP.PCAP.CD?end=2013\&amp;start=1960 (accessed December 11, 2019). 